\title{
Morphometric and Fractal Analysis of Injured Skeletal Muscle Tissue Subjected to A Combination of Treatments; Cryotherapy and Therapeutic Ultrasound
}

\author{
Análisis de la Morfometría y de la Dimensión Fractal en la Lesión del Tejido Muscular \\ Esquelético Expuesto en la Combinación de los Tratamientos de Crioterapia y Ultrasonido
}

Tatiana Emy Koike*; Regina Celi Trindade Camargo*; Guilherme Akio Tamura Ozaki**; Robson Chacon Castoldi**; Patrícia Monteiro Seraphim*; Sérgio Minoro Oikawa***; José Carlos Silva Camargo Filho*

KOIKE, T. E.; CAMARGO, R. C. T.; OZAKI, G. A. T.; CASTOLDI, R. C.; SERAPHIM, P. M.; OIKAWA, S. M \& CAMARGO FILHO, J. C. S. Morphometric and Fractal analysis of injured skeletal muscle tissue subjected to a combination of treatments; cryotherapy and therapeutic ultrasound. Int. J. Morphol., 34(3):1076-1082, 2016.

SUMMARY: The aim of this study was to analyze the effects of an association of cryotherapy and therapeutic ultrasound on the treatment of muscle injured by impact. Fifty-five Wistar rats were divided into five groups ( $\mathrm{n}=11$ ), Acute Injury (AI), Injury (I), Cryotherapy (CR), Therapeutic Ultrasound (TU) and Association of Cryotherapy and Therapeutic Ultrasound (CRTU). The CR and CRTU groups received applications of Cryotherapy three times (immediately, 24 and $48 \mathrm{~h}$ after injury) of 20 minutes duration. The TU and CRTU groups received applications of Therapeutic Ultrasound for seven days, for five minutes, in pulsed mode, $0.5 \mathrm{w} / \mathrm{cm}$ intensity, frequency $1 \mathrm{MHz}$. Body mass and gastrocnemius mass were analyzed. In addition to histological slides stained with hematoxylin and eosin used for morphometric analysis, picrosirius dye was used for quantification of collagen by Fractal Dimension (FD). The results of the intra-group analysis showed lower body mass and gastrocnemius in the CRTU group in relation to the AI $(p=0.001)$, I $(p=0.001)$, $\mathrm{CR}(\mathrm{p}=0.001)$ and TU groups $(\mathrm{p}=0.001)$, and lower values of FD to quantify collagen in the CRTU group in relation to the AI ( $\mathrm{p}=$ 0.007) and CR groups $(\mathrm{p}=0.014)$. In summary, the present study showed that the association of Cryotherapy with Therapeutic Ultrasound promoted better results in the aspects analyzed compared to application of the therapies in isolation.

KEY WORDS: Fractal; Regeneration; Cryotherapy; Ultrasound Therapy; Collagen.

INTRODUCTION

Muscle injuries often lead to removal from physical activities during the rehabilitation period, whether for sport or recreation. The main purpose of physical therapy is to act in the repair process, reducing the inflammatory process, accelerating tissue repair and inhibiting the occurrence of sequelae such as the formation of fibrosis (Mann et al., 2011).

Muscle injury stimulates the rupture of local myofibrils and blood vessels that promote leukocyte invasion in phagocytosis of damaged cells (Järvinen et al., 2013), besides the production and deposition of fibroblasts (Calvi et al., 2012). However, the exacerbated fibroblast deposition may result in fibrous tissue formation in the injured tissue, impairing the repair process and tissue function (Alves et al., 2014).
Cryotherapy (CR) is a low cost and easily applied technique that promotes localized cooling of tissues, vasoconstriction, which decreases cell metabolism, and limits the extent of inflammation in the tissue. However, its effects can delay the arrival of white blood cells and impair the following stages of the tissue repair process that involve the formation of new myofibrils and deposit of collagen fibers (Takagi et al., 2011).

The production of collagen fibers is important as these fibers give rise to extracellular matrix which has structural functions and promotes bonding and alignment between muscle fibers (Calvi et al.). Studies that investigated the application of Therapeutic Ultrasound (TU), found improved organization of cells and alignment of collagen fibers when

\footnotetext{
* "Júlio de Mesquita Filho" StateUniversityof São Paulo (FCT-UNESP), Presidente Prudente. Department of Physiotherapy, São Paulo,Brazil.

** University of Campinas (Unicamp), Campinas, Department of Medical Sciences, Campinas, Brazil.

**** "Júlio de Mesquita Filho" State University of São Paulo (FCT-UNESP), Presidente Prudente. Department of Statistics,São Paulo,Brazil.
} 
applied during the repair of skeletal muscle damage (Piedade et al., 2008).

Thus, TU in pulsed mode promotes ultrasonic waves that penetrate the tissue and generate vibrations at the cellular level, increasing permeability of the cellular membrane and the exchange of fluids, stimulating cell metabolism. This mechanical effect favors the process of resolution of inflammation, since the increased metabolism stimulates the activity of platelets, mast cells, macrophages and neutrophils when the tissue is involved in the inflammatory phase (Järvinen et al.).

It is known that skeletal muscle responds immediately to harmful stimulus, and applications of therapeutic resources promote beneficial changes in the resolution of inflammation and accelerate the regeneration of myofibrils. Therefore, therapeutic interventions in the muscle repair process such as CR combined with TU could influence the cellular events to a greater extent than these treatments applied in isolation. Thus the combination of these treatments could improve the repair process of muscle; since cryotherapy has the effect of retarding the inflammatory process and ultrasound promotes increased cell membrane permeability by stimulating the circulating fluid stream, reducing local edema and accelerating the resolution of inflammation.

Thereby, this study aimed to analyze the repair of skeletal muscle tissue, using a combination of cryotherapy and therapeutic ultrasound treatments, through analysis of body and muscle mass, measure of the smallest diameter of the muscle fibers and quantification of collagen through fractal dimension.

\section{MATERIAL AND METHOD}

Fifty five male Wistar rats (Rattus Norvegicus ), four months of age, were used, provided by the Central Biotherium of the São Paulo State University (UNESP), Botucatu-SP campus (Brazil), and maintained in the Laboratory of Histology and Histochemistry Facilities of the Faculty of Science and Technology - FCT/UNESP, Presidente Prudente campus, SP - Brazil. The animals were housed with four animals per cage with controlled temperature $\left(22 \pm 2{ }^{\circ} \mathrm{C}\right)$ and humidity $(50 \pm 10 \%)$ and a 12 hour light/dark cycle, with free access to water and food (MP-77, Primor). This project was approved by the Ethics Committee on Animal Use (CEUAs) of the Faculty of Science and Technology - FCT / UNESP, Presidente Prudente Campus - SP; Protocol no. 01/2014.

Experimental Groups: To assemble the experimental groups a Clustered Randomized Trial was performed. This procedure was performed in order to reduce the effects of experimental error caused by animal biological variations, such as weight variation, which could affect the amount of energy absorbed by the impact provided by the injury mechanism (Nogueira \& Gomes, 1978).

The animals weighed between 326 and $467 \mathrm{~g}$ and were divided into three groups, weight $\mathrm{I}(\mathrm{n}=18)$ : $326^{\text {' }} 366 \mathrm{~g}$; weight II ( $\mathrm{n}=19): 367,394 \mathrm{~g}$ and weight III $(\mathrm{n}=18): 395^{\prime} 467 \mathrm{~g}$. Next the animals were randomly selected and placed in each experimental group so that each group was composed of the same number of animals from the Weight I, II and III groups $(\mathrm{n}=11)$ and subjected to experimental procedures (Fig. 1):

- Acute Injury (AI): Subjected to muscle injury protocol and remained untreated for two days.

- Injury (I): Subjected to muscle injury protocol and remained untreated for seven days.

- Cryotherapy (CR): Subjected to muscle injury protocol, followed by cryotherapy protocol.

- Therapeutic Ultrasound (TU): Subjected to muscle injury protocol, followed by therapeutic ultrasound protocol.

- Cryotherapy + Ultra Sound Therapy (CRTU): Subjected to muscle injury protocol, followed by the combination of treatments: cryotherapy and therapeutic ultrasound.

Protocol of muscle injury: Impact injury equipment was used following the specifications of Stratton et al. (1984) (Fig. 2A). The animals were anesthetized through intraperitoneal administration of a combination of Ketamine $(70 \mathrm{mg} / \mathrm{kg})$ and Xylazine $(15 \mathrm{mg} / \mathrm{kg})$. After confirming the

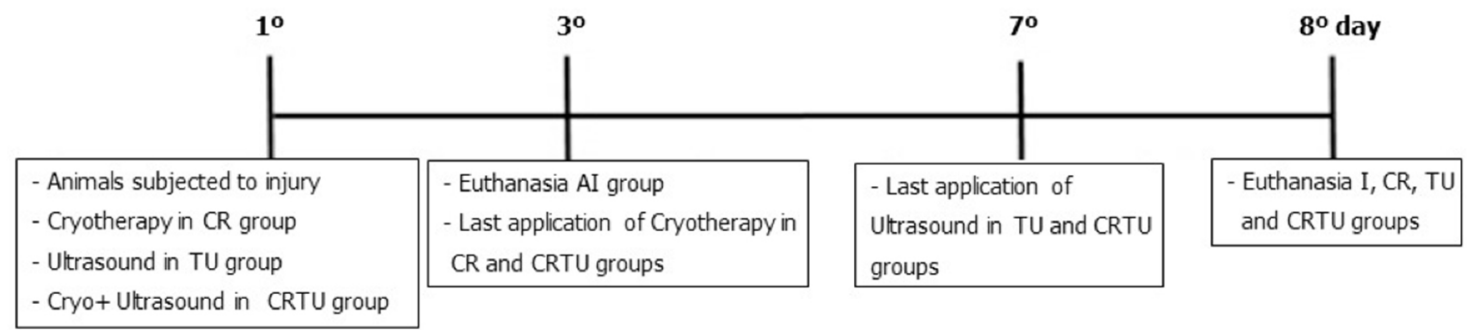

Fig. 1. Experimental procedures in days. 


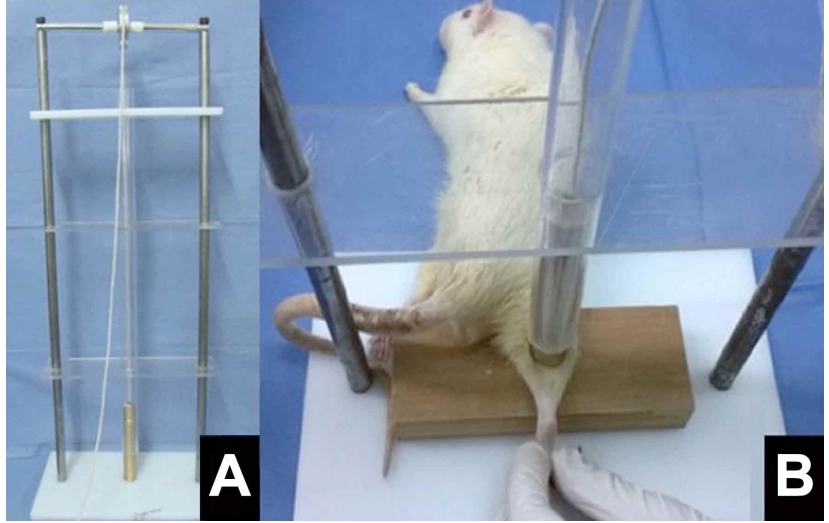

Fig. 2. A) Equipment used for muscle damage through impact. Two vertical metal rods of $60 \mathrm{~cm}$, plastic base with an area of 272.5 $\mathrm{cm}^{2}$, metal frame to support the pulley, wire attached to the load weighing $200 \mathrm{~g}$. B) Positioning of the right hindlimb in knee extension and dorsiflexion of the ankle to release the load on the belly of the gastrocnemius muscle of the animals.

anesthesia, the animals were placed in the injury equipment in a prone position keeping the right hindlimb in knee extension and the ankle at $90^{\circ}$ (Fig. 2B). A load of $200 \mathrm{~g}$ was released from a height of $30 \mathrm{~cm}$ directly onto the belly of the gastrocnemius muscle, promoting an impact injury without causing fracture.

Cryotherapy Protocol: The application of the Cryotherapy was performed three times: immediately, 24 hours and 48 hours after the muscle injury protocol in the CR and CRTU groups. Each application had a duration of 20 minutes (Takagi et al.), performed with the animals under anesthesia and in the supine position. Small templates were made with cardboard in a conical shape similar to the hindlimb of the animals, and a plastic bag containing water was frozen around the shape of the cardboard (Fig. 3A). Thus, the entire length of the hindlimb of the animal was surrounded by ice. The ice was fixed with adhesive tape over the entire extension of the hind limb, from the thigh to the ankle (Fig. 3B).

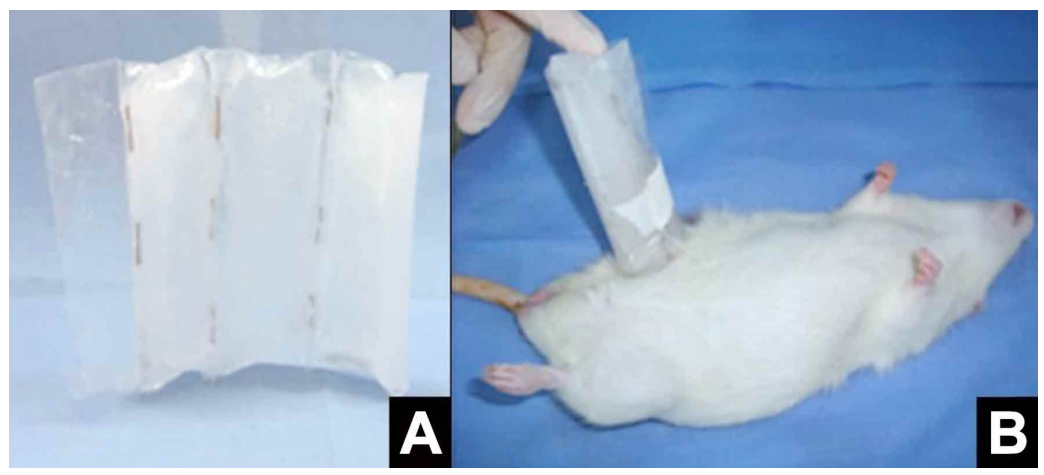

Fig. 3. A) Small plastic bags of conical shape for the hindlimb of the animals. B) The plastic bag with water frozen inside was fixed with adhesive tape over the hind limb, from the thigh to the ankle.
Protocol of Therapeutic Ultrasound: An AVATAR-V ${ }^{\circledR}$ device, KLD Biosystems Electronic Equipment LTD, was used, properly calibrated for the research, with an effective radiation area (ERA) of $1.0 \mathrm{~cm}^{2}$. Application was performed on the anesthetized animals for seven days, lasting five minutes, in pulsed mode, at an intensity of $0.5 \mathrm{~W} / \mathrm{cm}^{2}$ and frequency of $1 \mathrm{MHz}$ (Farcic et al., 2013). Water-soluble gel was used as a medium of conduction, making circular motions, focusing on the muscle belly region, where the injury had been induced (Piedade et al.).

\section{Protocol of Combination treatments (Cryotherapy +} Therapeutic Ultrasound): The combination of treatments was performed in the same manner as the aforementioned treatments, with ice being applied first followed by application of the ultrasound. After three days of ice application, the treatment continued with only the application of ultrasound until the end of the experimental period.

Collection of Material: Initial and final body weight were collected. After the experimental period the animals were euthanized by intraperitoneal application of an overdose of Ketamine and Xylazine, for subsequent collection and absolute weighing ( $\mathrm{g}$ ) of the right and left gastrocnemius muscles. The medial region of the right gastrocnemius muscle was used for preparation of histological slides.

For the analysis of Body Mass (BM), each animal was weighed before (BMbefore) and at the end (BMafter) of the experiment. The ratio of the gastrocnemius muscle mass to body mass was calculated, obtaining the Relative Mass (MRel) through the following equation:

$$
\text { MRel }=(\text { Mmuscle }(\mathrm{g}) / \text { BMAfter }(\mathrm{g})) * 100) .
$$

Histological slides of the right gastrocnemius muscles were made with cross-sections of $5 \mathrm{~mm}$, stained with hematoxylin-eosin (HE) (Ozaki et al., 2015). Images of the slides were captured (100 x magnifications) using a Nikon 50i microscope coupled to a camera, Infinity 1 . These images were used to perform the analysis of the smallest diameter of the muscle fibers by means of the NIS-Elements software (120 muscle fibers per animal), Camargo Filho et al. (2011).

In order to quantify the content of collagen, Fractal Dimension analysis (FD) was performed (Ozaki et al.) on slides stained with Sirius Red and photographed by a polarized light microscope (Leica DM 4000B) coupled to a Leica DFC500 camera 

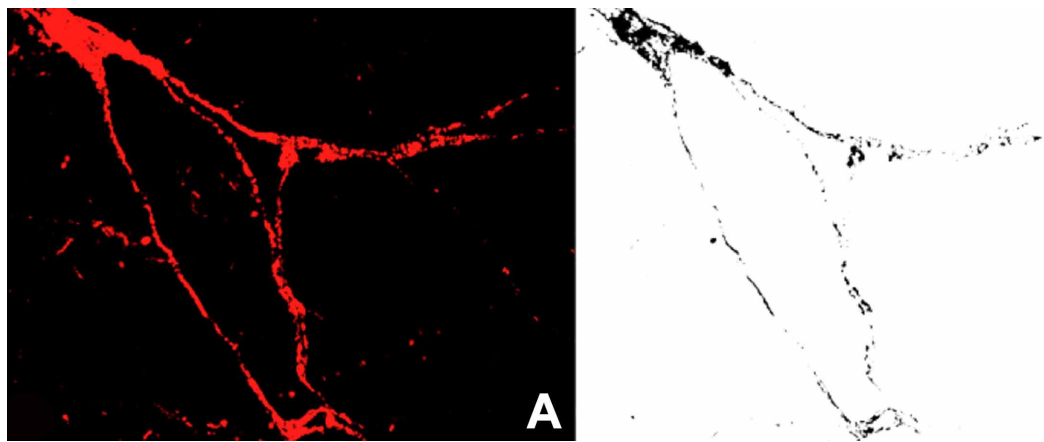

B

Fig. 4. Image of gastrocnemius muscle stained by the Picrosirius method (Increase 100x). a) Image taken in polarized light microscope showing the collagen in red. b) Image after the binarization process shows collagen in black and the rest of the cell blank, performed to measure DF.

with 100x magnification (Ozaki et al.), belonging to the Faculty of Dentistry -FOA / UNESP, Araçatuba - SP.

The Picrosirius images were passed through the binarization process, making them black and white. As a result of this process, the total collagen became black and the rest of the cells became white (Fig. 4). This was necessary as the FD analysis measures the black area of the image through the box-counting method. As this is a method to quantify the irregularity and complexity of the histological architecture, it can provide results without the interference of the appraiser, since the analysis is automatic and performed by the software (Ozaki et al.). All procedures were performed in ImageJ software, with the addition of Fractal Dimension and Lacunarity plugins, both available for free on the Internet (http://rsbweb.nih.gov/ij/) (Ozaki et al.).

Statistical Analysis. The Shapiro-Wilk test was used to verify data normality. For intra-group analysis of body mass,

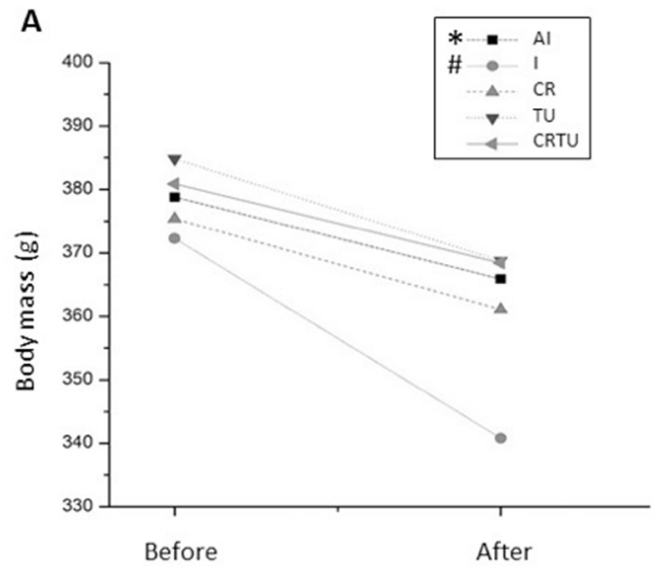

The animals submitted to the muscular injury protocol presented loss of body mass at the end of the experiment (Fig. 5A). For analysis of BM between groups the delta value was calculated but no significant differences were found.

For the BM intragroup analysis, a loss of body weight was observed between the beginning and the end of the experiment in the LA and L groups (Fig. 5A). In the treated groups, CR, TU and CRTU, no significant loss of BM was found.

The MRel presented a lower value of injured muscle, compared to non-injured muscle in the AI, I, CR and TU groups. Only the CRTU group was able to reduce (Fig. 5B).

Table I shows the results of quantitative analysis of histological changes observed in muscle fibers of the groups. The analysis of the smallest diameter of muscle fibers

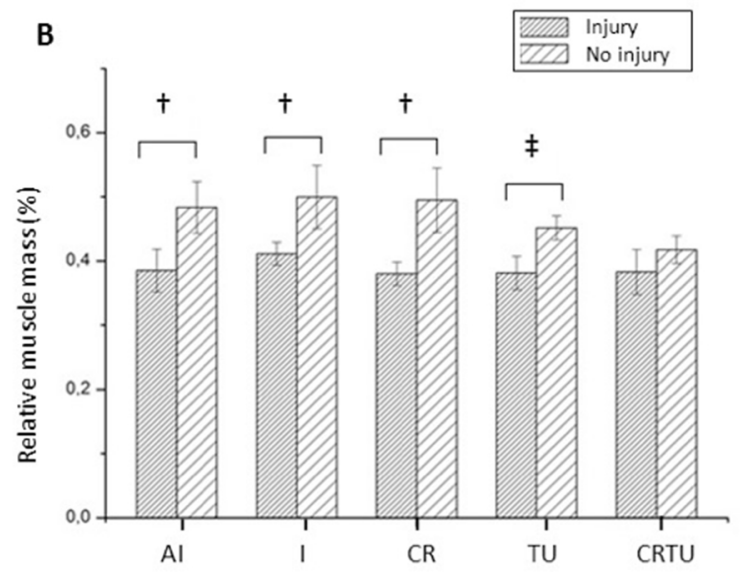

Fig. 5. A) graph depicting the evolution of BM before and after, expressed as mean values per group (g). * Significant difference between before and after values $(p=0.007)$; \# Significant difference between before and after values $(p=$ 0.003).B) Mean values and standard deviation of MRel. $\uparrow$ Significant difference compared to the uninjured side $(\mathrm{p}=$ $0.001) ; ~+$ Significant difference compared to the uninjured side $(\mathrm{p}=0.007)$. 
showed significant increase in fiber diameter in the AI group compared to the I $(\mathrm{p}=0.001), \mathrm{CR}(\mathrm{p}=0.001), \mathrm{TU}(\mathrm{p}=$ $0.001)$ and CRTU ( $p=0.001)$ groups; in the I group compared to the CR $(\mathrm{p}=0.001)$, TU $(\mathrm{p}=0.002)$ and CRTU $(\mathrm{p}=0.001)$ groups; in the CR group in relation to the TU ( $p$ $=0.001)$ and CRTU $(\mathrm{p}=0.001)$ groups; and in the TU group compared to the CRTU group ( $\mathrm{p}=0.001)$.

Fractal Dimension Analysis of collagen showed that the CRTU group presented a significantly decreased quantity of collagen compared with the LA $(\mathrm{p}=0.007)$ and CR groups $(\mathrm{p}=0.014)($ Table I).

Table I. Values of smallest diameter of the fibers and collagen Fractal Dimension.

\begin{tabular}{lcc}
\hline Groups & $\begin{array}{c}\text { Diameter of the } \\
\text { fibers }\end{array}$ & $\begin{array}{c}\text { Fractal } \\
\text { Dimension }\end{array}$ \\
\hline AI & $53.64 \pm 9.02 *$ & $1.26 \pm 0.13 \#$ \\
I & $46.70 \pm 7.25 *$ & $1.21 \pm 0.05$ \\
CR & $50.98 \pm 10.62^{*}$ & $1.26 \pm 0.10 \#$ \\
TU & $44.64 \pm 8.28 *$ & $1.15 \pm 0.02$ \\
CRTU & $42.04 \pm 7.47^{*}$ & $1.09 \pm 0.05$ \\
\hline
\end{tabular}

Values shown as means and standard deviations of the fiber diameter and Fractal Dimension. * Significant difference compared to all groups ( $\mathrm{p}<0.05$ ), \# significant difference compared to the CRTU group $(\mathrm{p}<0.05)$.

\section{DISCUSSION}

This study found that body weight reduced in all groups at the end of the experiment; however, this loss was not significant in the treated groups (CR, TU and CRTU). The relative mass of the gastrocnemius muscle presented significant reductions in the injured side compared to the non-injured side for the AI, I, Cr and TU groups. The measure of the smallest diameter of the fibers showed a significant difference between all groups, although the CRTU group showed the lowest measure of fiber diameter. Furthermore besides the TU and CRTU groups presenting reduced FD of collagen, the combination of treatments demonstrated better aspects in morphometric measurements and body and muscle mass; evidencing better tissue repair than the treatments in isolation.

The body weight loss observed in all groups can be attributed to the stress to which the animals were submitted, which could have interfered in the diet and/or metabolism of the animals (Botelho et al., 2007). Moreover, except the
CRTU group, the other experimental groups presented a significant decrease in muscle mass in the injured hindlimb compared to the uninjured side. This may be at least partly related to the increase in pro-inflammatory factors, and could result in proteolysis.

The intragroup comparison showed that all groups lost body mass at the end of the experiment, however there was no difference between groups. Thus, the increase in local inflammation could be related to loss of body and muscle mass in the lesioned animals. The experimental model of impact injury used has been proven (Martins et al., 2015) to be able to promote rupture of the fibers and thus, the inflammation process. Therefore, local inflammation may be related to the loss of body and muscle mass in the lesioned animals. According to Li et al. (2001), increased inflammation leads to loss of muscle proteins, as observed in myocytes exposed to pro-inflammatory cytokines, such as tumor necrosis factor-alpha (TNF-a). In the present study, it is probable that the combination of treatments promoted the reduction in the inflammatory process observed through the minor loss of body and muscle mass and reduction in the diameter of the fibers.

For the morphometric analysis, the AI, I, CR and TU groups showed higher values of diameters of fibers. Thus the inflammatory process may have caused edema in the cytoplasm (Kumar et al., 2010), featuring an increase in the cross section of the muscle cells. The results showed that all treatments reduced the diameter of the fibers but the combination of cryotherapy techniques and therapeutic ultrasound potentiated the reduction $(42.04 \mathrm{mM})$, possibly by attenuating inflammation.

Fractal analysis demonstrated a reduction in the quantity of collagen in animals that received applications of therapeutic ultrasound and combination of treatments. This analysis quantified the collagen types I, II and III so the result of the analysis corresponds to the total collagen of muscle tissue (Ozaki et al.).

In the present study, it was observed that collagen increased in the CR group compared to the CRTU group. This result corroborates Takagi et al., who examined the influence of cryotherapy in muscle injury and demonstrated that the application of ice after 4 days delayed regeneration of myofibers, and when observed after 14 and 28 days, induced collagen deposition around the regenerating muscle fibers due to the increase in production of TGF-b1.

The therapeutic ultrasound (TU group) promoted a reduction in the diameter of muscle fibers in relation to the IA, I and CR groups; besides reducing the amount of collagen. 
Therapeutic ultrasound assists the repair of muscle injury by altering the activity of neutrophils and macrophages involved in the inflammatory phase, accelerating the process of muscle repair, mainly through mechanical effects (Burks et al., 2011). Thus, its performance is characterized by increased synthesis of myogenic precursor cells and fibroblast proliferation (Piedade et al.). Therefore the use of therapeutic ultrasound was effective at attenuating tissue inflammation.

At the site of injury, collagen production is stimulated due to restructure of the extracellular matrix, contributing to scar tissue formation. This response is initially beneficial as it protects the site of injury, however, the exacerbated production of collagen in the injury area impairs muscle function, causing pain, in addition to making the muscle more susceptible to recurrent injuries and loss of muscle function (fibrosis) (Ciciliot \& Schiaffino, 2010). Studies have shown that about seven days after muscle injury an increase in collagen occurs in this tissue, and the increase and accumulation of collagen can be prognostic of fibrosis after total tissue repair (Alves et al.).

Thus, it is important to analyze and understand the effects of the treatments applied in muscle repair regarding both histological features and aspects related to the production of collagen fibers. Analyzes that provide the quantification of collagen in injured and treated muscles can help physical therapists and physicians to determine the appropriate treatment, contributing to better repair of muscle damage (Calvi et al.).

The results of this study demonstrate the superiority of the combination of treatments protocol to accelerate muscle repair by reducing the inflammatory process and preventing the formation of fibrosis through reduction in the quantity of collagen at the site of muscle injury. A reduction in inflammation was observed in the study of Martins et al., who compared cryotherapy techniques, therapeutic ultrasound and a combination of techniques in muscle injury, demonstrating that the combination of cryotherapy and therapeutic ultrasound in injured muscle tissue was better than the treatments applied individually, by promoting a reduction in inflammatory markers on blood plasma and consequently accelerating resolution of the inflammatory process.

However no studies were found in the literature on the combination of treatments in the histological repair and its effect on collagen production. The results found in the present study indicate that cryotherapy combined with therapeutic ultrasound benefits the process of tissue repair within seven days after the injury, reducing the chances of fibrosis.
Some limitations of this study should be mentioned, such as the lack of a control group (without intervention), and it not being possible to discuss the body mass variable as this study aimed to analyze changes in skeletal muscle tissue. Although this study used a clustered randomized method to reduce the biological experimental error, there may have been variation in the location of muscle damage, since variations in the anatomical position of the muscles have been shown.

Further studies are recommended to analyze the quantity of collagen and organization in muscle tissue damaged by impact, as well as to quantify the different collagen types (I, II and III). Furthermore, studies with a longitudinal design to investigate different stages of the repair process could be useful. Studies on the treatment of muscle injuries could provide information which enable development of a more effective treatment protocol, both for researchers and clinicians working in health and muscle injuries.

In conclusion, the combination of treatments, within seven days, was better than cryotherapy and therapeutic ultrasound treatments in isolation, promoting a reduction in body and muscle loss; in addition to reducing the expansion of cytoplasm and the quantity of collagen.

KOIKE, T. E.; CAMARGO, R. C. T.; OZAKI, G. A. T.; CASTOLDI, R. C.; SERAPHIM, P. M.; OIKAWA, S. M \& CAMARGO FILHO, J. C.S. Análisis de la morfometría y de la dimensión fractal en la lesión del tejido muscular esquelético expuesto en la combinación de los tratamientos de crioterapia y ultrasonido. Int. J. Morphol., 34(3):1076-1082, 2016.

RESUMEN: El objetivo del estudio fue evaluar los efectos de la asociación de las técnicas de crioterapia y ultrasonido terapéutico en el tratamiento de la lesión muscular por impacto. Fueron utilizadas 55 ratas Wistar, expuestas a lesión y separadas en grupos $(n=11)$ : Lesión aguda (LA), Lesión (L), Crioterapia (CR), Ultrasonido Terapéutico (UT) y Crioterapia + Ultrasonido Terapéutico (CRUT). Los grupos CR y CRUT recibieron la aplicación, durante 20 minutos, en tres momentos (inmediatamente, 24 y 48 horas, después de la lesión). Los grupos UT y CRUT, recibieron UT por siete días, con una duración de cinco minutos, en modo pulsado, con una intensidad de $0,5 \mathrm{~W} / \mathrm{cm}^{2}$ y frecuencia de 1 MHz. Fueran medidos el peso corporal y el peso de los músculos gastrocnemios y se realizaron cortes histológicos del músculo gastrocnemio, los cuales fueron teñidos con hematoxilina-eosina (HE) para el análisis morfométrico y con picrosirius para el análisis del colágeno por dimensión fractal (DF). Los resultados de los análisis intragrupo demostraron una menor disminución de la masa coporal y muscular en el grupo CRUT. Además, fue observado un valor inferior en la morfometría en el grupo CRUT en comparación a los grupos LA $(p=0,001), L(p=0,001), C R(p=0,001)$ y 
KOIKE, T. E.; CAMARGO, R. C. T.; OZAKI, G. A. T.; CASTOLDI, R. C.; SERAPHIM, P. M.; OIKAWA, S. M \& CAMARGO FILHO, J. C. S. Morphometric and Fractal analysis of injured skeletal muscle tissue subjected to a combination of treatments; cryotherapy and therapeutic ultrasound. Int. J. Morphol., 34(3):1076-1082, 2016.

UT ( $\mathrm{p}=0,001)$, y un menor valor de la DF con respecto al colágeno en el grupo CRUT en comparación a los grupos LA $(\mathrm{p}=0,007)$ y $\mathrm{CR}(\mathrm{p}=0,014)$. En síntesis, el presente estudio demostró que el protocolo de asociación de las técnicas de CR y UT causaron mayores respuestas benéficas en los aspectos analizados en comparación a los protocolos con los tratamientos aplicados de forma aislada.

PALABRAS CLAVE: Análisis fractal; Regeneración; Crioterapia; Ultrasonido Terapéutico; Colágeno.

\section{REFERENCES}

Alves, A. N.; Fernandes, K. P.; Melo, C. A.; Yamaguchi, R. Y.; França, C. M.; Teixeira, D. F.; Bussadori, S. K.; Nunes, F. D. \& Mesquita-Ferrari, R. A. Modulating effect of low level-laser therapy on fibrosis in the repair process of the tibialis anterior muscle in rats. Lasers Med. Sci., 29(2):813-21, 2014.

Botelho, A. P.; Facio, F. A. \& Minamoto, V. B. Regeneração do músculo tibial anterior em diferentes períodos após lesão por estimulação elétrica neuromuscular. Rev. Bras. Fisioter., 11(2):99-104, 2007.

Burks, S. R.; Ziadloo, A.; Hancock, H. A.; Chaudhry, A.; Dean, D. D.; Lewis, B. K.; Frenke, V. \& Frank, J. A. Investigation of cellular and molecular responses to pulsed focused ultrasound in a mouse model. PloS One,6(9):e24730, 2011.

Calvi, E. N.; Nahas, F. X.; Barbosa, M. V.; Calil, J. A.; Ihara, S. S.; Silva, Mde. S.; Franco, M. F. \& Ferreira, L. M. An experimental model for the study of collagen fibers in skeletal muscle. Acta Cir. Bras., 27(10):681-6, 2012.

Camargo Filho, J. C. S.; Garcia, B. C.; Kodama, F. Y.; Bonfim, M. R.; Vanderlei, L. C. M.; Ramos, E. M. C.; Camargo, R. C. T.; Padulla, S. A. T. \& Maeda, J. K. Efeitos do exercício aeróbio no músculo esquelético de ratos expostos à fumaça de cigarro. Rev. Bras. Med. Esporte, 17(6):416-9, 2011.

Ciciliot, S. \& Schiaffino, S. Regeneration of mammalian skeletal muscle. Basic mechanisms and clinical implications. Curr. Pharm. Des., 16(8):906-14, 2010.

Farcic, T. S.; Baldan, C. S.; Cattapan, C. G.; Parizotto, N. A.; João, S. M. \& Casarotto, R. A. Treatment time of ultrasound therapy interferes with the organization of collagen fibers in rat tendons. Braz. J. Phys. Ther., 17(3):263-71, 2013.

Järvinen, T. A.; Järvinen, M. \& Kalimo, H. Regeneration of injured skeletal muscle after the injury. Muscles Ligaments Tendons J., 3(4):337-45, 2013.

Kumar, V.; Abbas, A. K.; Fausto, N. \& Aster, J. C. Robbins and Cotran. Pathologic Basis of Disease. Philadelphia, Saunders/ Elsevier, 2010.
Li, Y. P. \& Schwartz, R. J. TNF-alpha regulates early differentiation of $\mathrm{C} 2 \mathrm{C} 12$ myoblasts in an autocrine fashion. F. A. S. E. B. J., 15(8):1413-5, 2001.

Mann, C. J.; Perdiguero, E.; Kharraz, Y.; Aguilar, S.; Pessina, P.; Serrano, A. L. \& Muñoz-Cánoves, P. Aberrant repair and fibrosis development in skeletal muscle. Skelet. Muscle, 1(1):21, 2011.

Martins, C. N.; Moraes, M. B.; Hauck, M.; Guerreiro, L. F.; Rossato, D. D.; Varela, A. S. Jr.; da Rosa, C. E. \& Signori, L. U. Effects of cryotherapy combined with therapeutic ultrasound on oxidative stress and tissue damage after musculoskeletal contusion in rats. Physiotherapy, pii:S0031-9406(15)038559, 2015.

Nogueira, M. C. S. \& Gomes, F. P. Delineamento em blocos casualizados completos aumentados. An. Esc. Super. Agric. Luiz de Queiroz, 35:225-41, 1978.

Ozaki, G.; Camargo, R. C. T.; Koike, T. E.; Garcia, T. A.; Castoldi, R. C. \& Camargo Filho, J. C. Fractal analysis of skeletal muscle tissue of rats subjected to stretch injury. Int. J. Morphol., 33(3):908-13, 2015.

Piedade, M. C.; Galhardo, M. S.; Battlehner, C. N.; Ferreira, M. A.; Caldini, E. G. \& de Toledo, O. M. Effect of ultrasound therapy on the repair of gastrocnemius muscle injury in rats. Ultrasonics, 48(5):403-11, 2008.

Stratton, S. A.; Heckmann, R. \& Francis, R. S. Therapeutic Ultrasound: Its Effects on the lntegrity of a Nonpenetrating Wound. J. Orthop. Sports Phys. Ther., 5(5):278-81, 1984.

Takagi, R.; Fujita, N.; Arakawa, T.; Kawada, S.; Ishii, N. \& Miki, A. Influence of icing on muscle regeneration after crush injury to skeletal muscles in rats. J. Appl. Physiol., 110(2):382-8, 2011.
Correspondence Address Tatiana Emy Koike

Rua Roberto Simonsen, 305

19060-900 - P. Prudente, SP

Telephone: (18) 3229- 5822

São Paulo

BRASIL

Email: tatiemykoike@gmail.com

Received: 24-03-2016

Accepted: 22-06-2016 